[Agr. Biol. Chem., Vol. 30, No. 11, p. 1106 1111, 1966]

\title{
Studies on Herbicides and Plant Growth Regulators
}

\section{Part III. Synthesis and Structures of N-Aryloxyacylazoles*}

\author{
By Michihiko Ochial and Toshiya Kamikado
}

\author{
Research and Development Division, Takeda Chemical Industries, Ltd., Osaka \\ Received May 18, 1966
}

\begin{abstract}
With the aim of obtaining plant growth regulators, we have synthesized 1-aryloxyacylbenzimidazoles, 1-aryloxyacylindazoles, 2-aryloxyacyl-4,5,6,7-tetrahydroindazoles and 1aryloxyacylbenzotriazoles by the acylation of azoles, and 1-aryloxyacyl-4,5,6,7-tetrahydroindazoles by the reaction of aryloxyacylhydrazines with 2-(hydroxymethylene)cyclohexanone. The structures of these compounds are discussed on the basis of nuclear magnetic resonance data.
\end{abstract}

In the preceding paper, ${ }^{11}$ we have described the synthesis, structural evidence and some reactions of $\mathrm{N}$-aryloxyacylpyrazoles. The infrared absorption spectra of these compounds exhibited the carbonyl bands at the region of higher frequencies $\left(1730 \sim 1780 \mathrm{~cm}^{-1}\right)$ as expected, and their high chemical reactivities were observed.

It has been known ${ }^{2)}$ that $\mathrm{N}$-acetyl-benzimidazole and -benzotriazole exhibit the carbonyl bands at higher frequencies $\left(1729,1735 \mathrm{~cm}^{-1}\right.$ respectively) and bear high chemical reactivities. Our assumption, therefore, was that $\mathrm{N}$ aryloxyacyl derivatives of these azoles should be highly reactive, and might be qualified as a novel type of plant growth regulator different from the substituted aryloxyacyl amines.

The present paper deals with the synthesis, structure and some reactions of $\mathrm{N}$-aryloxyacyl derivatives of benzimidazole, benzotriazole and structurally related azoles, i.e. indazole and 4,5,6,7-tetrahydroindazole.

* This paper was presented at the 223rd Meeting of the Kansai Division of the Agricultural Chemical Society of Japan, Kochi, Nov., 1965, and a part of this work has already been presented in a preliminary communication: M. Ochiai and T. Kamikado, Chem. Pharm. Bull, 12, 1515 (1964).

1) Part I. M. Ochiai, Chem. Pharm. Bull., 12, 1101 (1964). Part II. M. Ochiai and T. Kamikado, Chem. Pharm. Bull., 14, 628 (1966).

2) H. A. Staab, Angew, Chem., 74, 704 (1962).

\section{Synthesis of N-Aryloxyacylazoles}

1-Aryloxyacylbenzimidazoles, 1-aryloxyacylindazoles, 2-aryloxyacyl-4,5,6,7-tetrahydroindazoles and 1-aryloxyacylbenzotriazoles were prepared by the reaction of aryloxyacyl chlorides with the azoles at $5 \sim 10^{\circ} \mathrm{G}$ in pyridine (Method A). Some 1-aryloxyacyl-4,5,6,7-tetrahydroindazoles were obtained by the reaction of aryloxyacylhydrazines with 2-(hydroxymethylene)cyclohexanone (Method B). The melting points, yields and elemental analyses of the compounds obtained are summarized in Table I.

\section{Structure}

The acylation of indazole should, theoretically, lead to two isomers, namely I and II. Auwers et al. ${ }^{3)}$ have recorded that the acylation of indazole at lower temperatures $(-15 \sim$ $0^{\circ} \mathrm{C}$ ) led to 2-acylindazoles (II) in many cases, while at higher temperatures gave rise to 1acylindazoles (I).

We carried out the acylation of indazole at higher temperature $\left(5 \sim 10^{\circ} \mathrm{C}\right)$ to obtain the corresponding 1-aryloxyacylindazoles. It was assumed that, in the NMR spectrum of 1aryloxyacylindazoles, the 3-proton signal would

3) a) K. v. Auwers, Ber., 58, 2081 (1925); b) K. v. Auwers und W. Demuth, $A n n, 45 i, 282$ (1926). 
$\int_{0}^{z}$

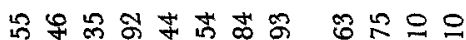

$\infty \infty \pi n \infty \infty ⿻$

$\dot{\infty} \infty \infty i \infty$

8 \&

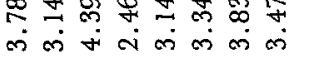

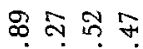

กิ ฒ

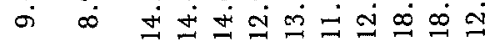

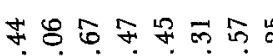

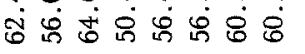

의 भु

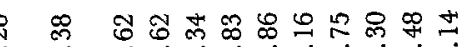

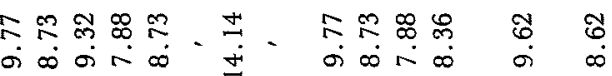

ชิ

$\infty$ ڤ

$\frac{0}{2} \int_{0}^{z}$

ชิ

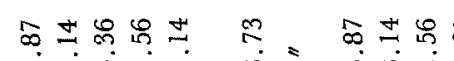

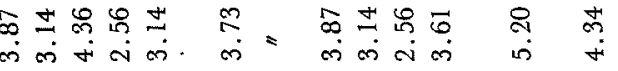

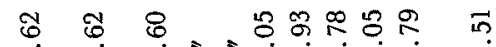

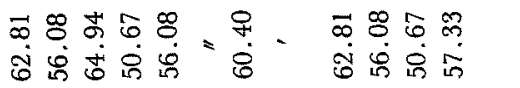

농 와

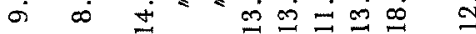

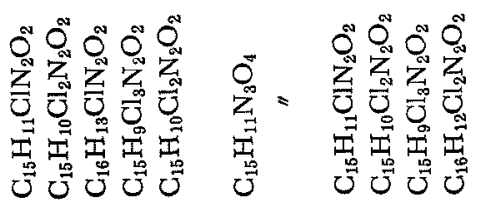

兽

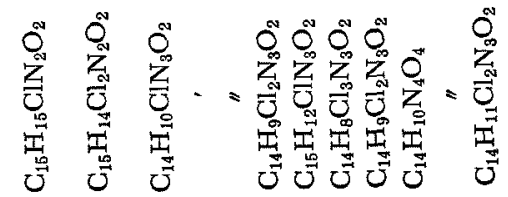

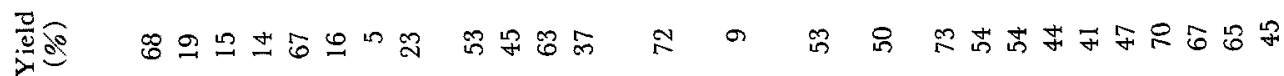

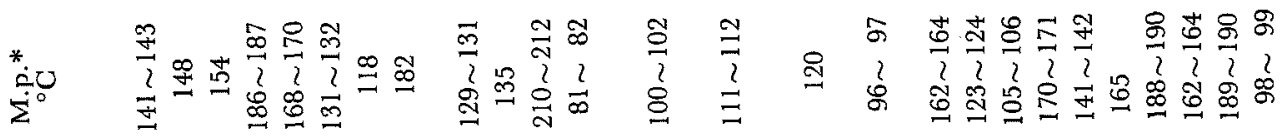

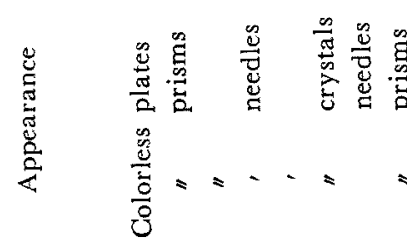

焉总焉

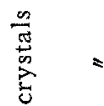

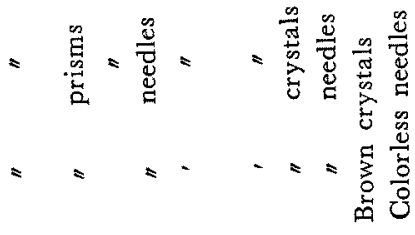

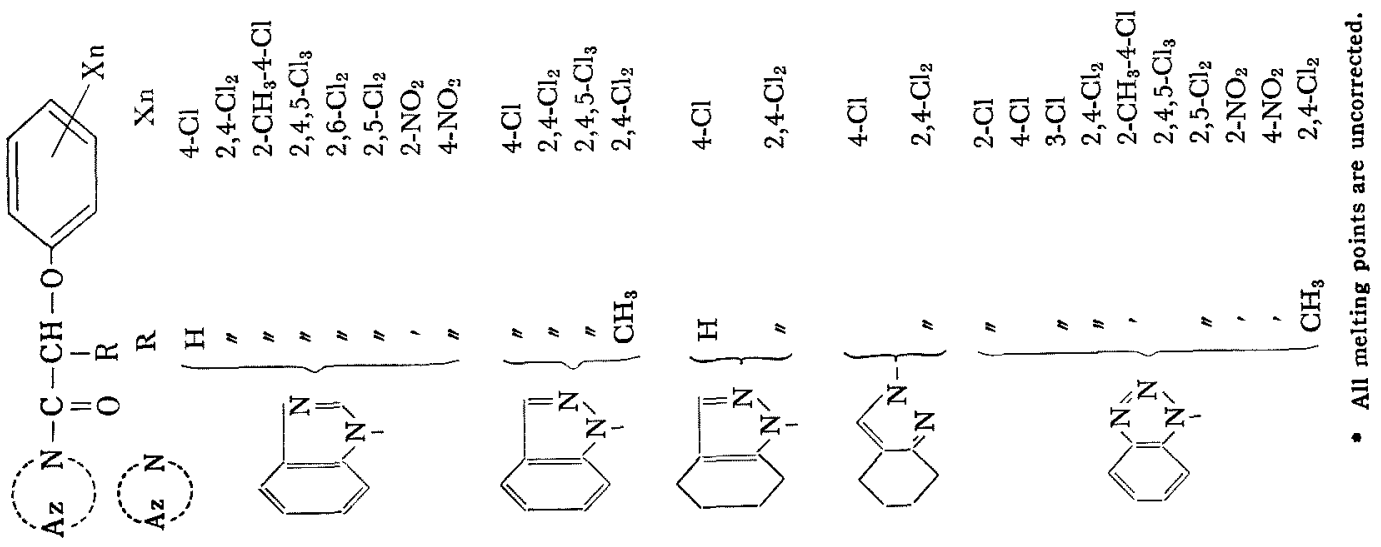




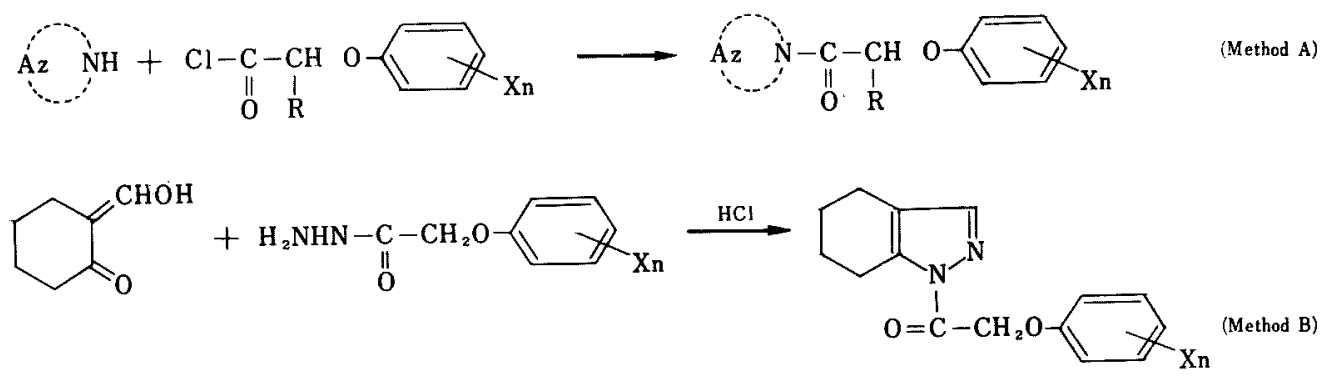

Table II. Nuclear Magnetic Resonance SPECTRA OF SOME N-ACYLINDAZOLES

No.<smiles>[R]C(C)(C)N=Cc1ccccc1</smiles>

$$
\mathrm{R}=
$$

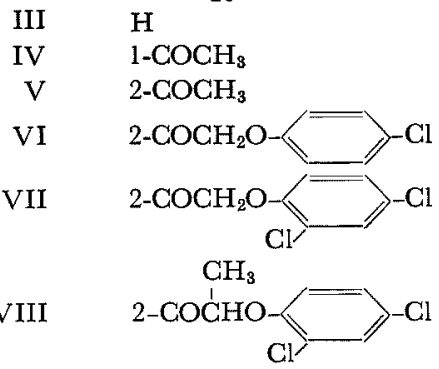

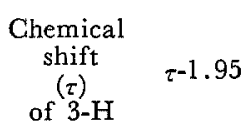

1.95

$1.87-0.08$

$1.24-0.63$

$1.80-0.15$

$1.81-0.14$<smiles>[R]C(=O)n1ncc2ccccc21</smiles><smiles>[R]C(=O)n1cc2ccccc2n1</smiles>

II

appear at higher fields than that of 2-aryloxyacylindazoles being due to less electron withdrawing and anisotropic effects of the carbonyl group. Indeed, this was confirmed with model compounds, 1- and 2-acetylindazoles $(\mathrm{IV}, \mathrm{V}),{ }^{\mathrm{sb}, 4)}$ as shown in Table II. Further1.76-0.19 more, our assumption was consistent with the earlier observation ${ }^{5)}$ that the $\mathrm{N}$-acylation of

Table III. Chemical Shift ( $\tau$ ) of 3-Proton of some N-ACYL-4,5,6,7-Tetrahydroindazoles<smiles>[R]OC([R])N1CCCCC1</smiles>

$\mathrm{C}_{6} \mathrm{H}_{5}$<smiles>O=[N+]([O-])c1ccccc1</smiles>

$\mathrm{CH}_{3}$<smiles>COc1cc[14c](Cl)cc1</smiles><smiles>COc1ccc(Cl)cc1Cl</smiles>

* $2.91=\tau$ of 3 -proton of 4,5,6,7-tetrahydroindazole.

\section{Product by the method A}

No. 3-H $\tau-2.91$ *

IX

1.91

$$
-1.00
$$

$\mathrm{X}$

$$
1.88
$$$$
-1.03
$$

$-0.84$

XII

2.07

$-0.84$

2.00

$-0.91$

4) K. v. Auwers und H. G. Allardt, Ann., 438, 1 (1924).

5) G. S. Reddy, L. Mandell and H. H. Geldstein, J. Chem. Soc., 1963, 1414.

\section{Product by the method $\mathrm{B}$}

$\overbrace{\text { No. } \quad 3-\mathrm{H}}^{\tau-2.91}$ *

IX'

2.53

$-0.38$

$\mathrm{X}^{\prime}$

2.67

$-0.28$

$\mathrm{XI}^{\prime}$

2.59

$-0.32$

XII'

2.55

$-0.36$

XIII'

2.53

$-0.38$ 
the benzimidazoles and purines caused fairy large down-field shift of the proton adjacent to the carbonyl group.

Since the chemical shifts of the 3-proton of the $\mathrm{N}$-aryloxyacylindazoles obtained appeared near $1.87 \tau$ rather than $1.24 \tau$, the compounds were assigned 1-aryloxyacylindazoles (VI VIII).
$\mathrm{N}$-Acyl-4,5,6,7-tetrahydroindazoles obtained by both methods (A and B) were isomeric. Auwers $^{6}$ ) assigned the 1-acyl structure to the products (IX, X) obtained by the method A. Similarly, the compounds (IX', $\mathrm{X}^{\prime}$ ) obtained by the method $\mathrm{B}$ were assigned the 2-acyl structure without sufficient evidence for the assignments. The NMR spectra of N-aryloxy-

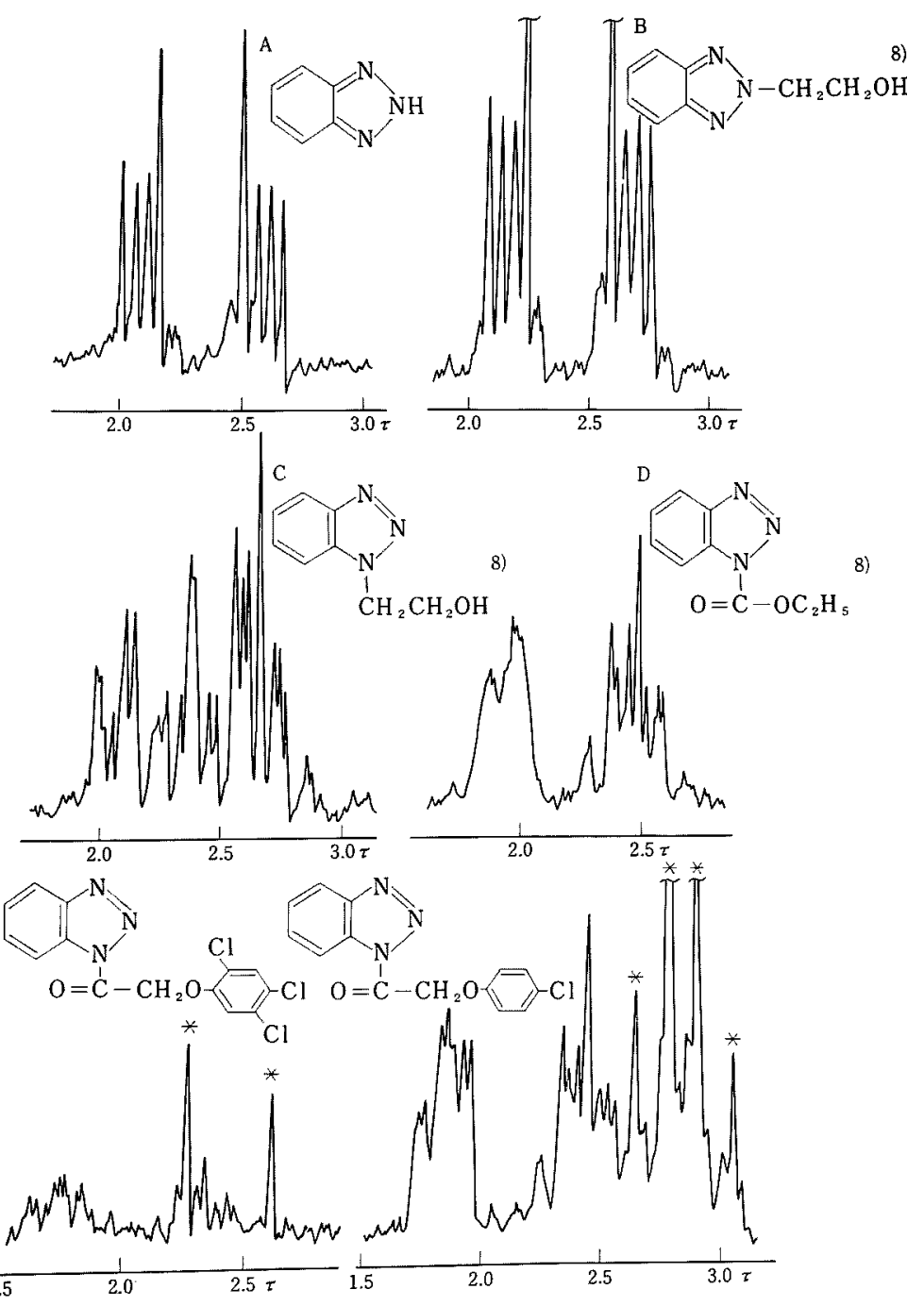

FIG. 1. NMR Spectra of Benzotriazole Derivatives, at 60 Mc. in Dioxane Containing Tetramethylsilane as an Internal Reference.

* Ring protons of the phenoxy part. 
acyl-4, 5, 6, 7-tetrahydroindazoles (XII, XIII, $\mathrm{XII}^{\prime}, \mathrm{XIII}^{\prime}$ ) obtained by our hands and of $\mathrm{N}$-acyl compounds (IX $\sim \mathrm{XI}, \mathrm{IX}^{\prime} \sim \mathrm{XI}^{\prime}$ ) prepared according to the procedure of Auwers ${ }^{6)}$ are listed in Table III.

The larger down-field shift of the 3-proton signal was observed with the products obtained by the method $A$, thus indicating that these compounds have to be assigned the 2-acyl-4, 5,6,7-tetrahydroindazoles. The structural assignments made by Auwers et al., therefore, have to be reinvestigated.

Acylation of benzotriazole should give an unsymmetric compound (XIV) and a symmetric one (XV). In the symmetric model compounds, the aromatic protons exhibited the pattern of $\mathrm{A}_{2} \mathrm{~B}_{2}$ system in the NMR spectrum (Fig. 1, $\mathrm{A}, \mathrm{B})$, while in the unsymmetric compounds this pattern disappeared (Fig. 1, C, D).<smiles>[R]C(=O)n1nnc2ccccc21</smiles>

XIV<smiles>[R]C(=O)n1nc2ccccc2n1</smiles>

IN
Since the NMR spectra of N-aryloxyacylbenzotriazoles synthesized showed no $\mathrm{A}_{2} \mathrm{~B}_{2}$ pattern, these compounds should be assigned 1-aryloxyacylbenzotriazoles (XIV).

Reactions of N-Aryloxyacylazoles

As was expected, $\mathrm{N}$-aryloxyacylazoles obtained revealed the carbonyl bands at high frequencies in the IR spectra (Table IV). This suggests that these $\mathrm{N}$-aryloxyacylazoles as has been known with $\mathrm{N}$-aryloxyacylpyrazoles $^{1)}$ and other azolides ${ }^{21}$ would be highly
TABLE IV. INFRARED DATA OF N-ARYLOXYACYLAZOLES AND YIELD OF 4-GHLOROPHENOXYACETANILIDE (XVI)

Structure $\mathrm{C}=\underset{\text { in nujol }}{\mathrm{O}\left(\mathrm{cm}^{-1}\right)} \quad$ Yield of XVI<smiles>c1ccc2nncnc2c1</smiles>
1755 98<smiles>CCCCC(C)=O</smiles><smiles></smiles>

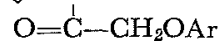<smiles>O=CC(=O)n1ncc2ccccc21</smiles>
89<smiles>CCCCCCCCCCOCC(=O)n1cc2c(n1)CCCC2</smiles>
1742 93<smiles>[CH2+]C1C=CC(Cl)CC1</smiles>

reactive for nucleophilic attack. This was substantiated by the fact that these compounds readily gave the anilide (XVI) upon treatment with aniline in benzene solution at $50^{\circ} \mathrm{C}$ for two hours. The results are summarized in Table IV.

As has already been known ${ }^{6 /}$ with 1-benzoyl4,5,6,7-tetrahydroindazole (IX'), 1-aryloxyacyl$4,5,6,7$-tetrahydroindazoles $\left(\mathrm{XII}^{\prime}, \mathrm{XIII}\right.$ ) isomerized on heating at $125^{\circ} \mathrm{C}$ to 2-aryloxyacyl compounds (XII, XIII).

\section{EXPERIMENTAL}

All melting points are uncorrected. Infrared absorption spectra were recorded with a Hitachi EPI-S2 infrared spectrometer and nuclear magnetic resonance

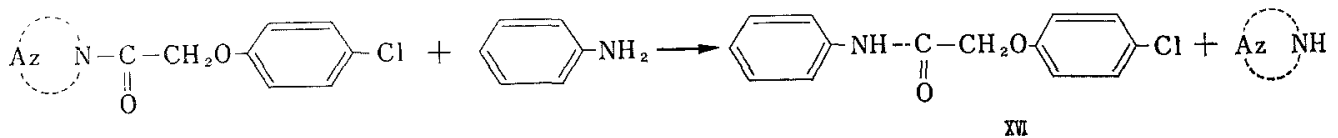

6) K. v, Auwers, Ann., 453, 211 (1927).

7) K. v. Auwers, W. Bushmann und R. Heidenreich, ibid., 435, 277 (1924).

8) F. Krollpfeiffer, H. Pötz und A. Rosenberg, Ber., 71, 596 (1938).

9) Org. Syntheses, 39, 27 (1959). 
spectra were measured in dioxane containing tetramethylsilane as an internal reference at $60 \mathrm{Mc}$. with a Varian A-60 spectrometer. For the preparation of compounds, typical runs are described.

\section{1-(4-Chlorophenoxyacetyl)benzotriazole (Method} A).

To a solution of $3.3 \mathrm{~g}$ of benzotriazole in $20 \mathrm{ml}$ of pyridine was added dropwise with stirring a solution of $5 \mathrm{~g}$ of 4-chlorophenoxyacetyl chloride in $5 \mathrm{ml}$ of acetone at $5 \sim 10^{\circ} \mathrm{C}$ over a period of $15 \mathrm{~min}$. After being stirred at room temperature for $1 \mathrm{hr}$., the reaction mixture was poured into $200 \mathrm{ml}$ of water and the separated solid was recrystallized from acetone to give colorless prisms, m.p. $123 \sim 4^{\circ} \mathrm{C}$; yield, $3.7 \mathrm{~g}$. Analytical data are given in Table I.

1-(4-Chlorophenoxyacetyl $)-4,5,6,7$-tetrahydroindazole (Method B).

To a solution of $0.6 \mathrm{~g}$ of 2-(hydroxymethylene) cyclohexanone ${ }^{9 /}$ and $1 \mathrm{~g}$ of 4-chlorophenoxyacetylhydrazine in $50 \mathrm{ml}$ of ethanol were added 2 drops of $10 \%$ hydrochloric acid. After being kept standing overnight at room temperature, the separated crystals were collected by suction and recrystallized from ethanol to give colorless crystals, m.p. $100 \sim 102^{\circ} \mathrm{C}$; yield, $1 \mathrm{~g}$. Analytical data are given in Table $\mathrm{I}$.

Reaction of N-Aryloxyacylazoles with Aniline.

An equimolar mixture of $\mathrm{N}$-(4-chlorophenoxyacetyl)azole and aniline in dry benzene was kept standing at $50^{\circ} \mathrm{C}$ for $2 \mathrm{hrs}$. Benzene was evaporated under reduced pressure taking care to keep the temperature below $40^{\circ} \mathrm{C}$, and the residue was poured into $10 \%$ hydrochloric acid. The separated solid was collected and digested with $5 \%$ aqueous sodium hydroxide at $80^{\circ} \mathrm{C}$ for $5 \mathrm{~min}$. to hydrolyse unreacted $\mathrm{N}$-(4-chlorophenoxyacetyl)azole. After cooling, the separated solid was collected and washed with $10 \%$ hydrochloric acid and then with water, and recrystallized from $90 \%$ ethanol to give colorless needles, m.p. $125^{\circ} \mathrm{C}$. The IR spectrum (in nujol) of this compound was identical with that of 4-chlorophenoxyacetanilide ${ }^{10}$ prepared by the reaction of aniline with 4-chlorophenoxyacetyl chloride.

Thermal Isomerization of 1-Aryloxyacy l-4,5,6,7tetrahydroindazole.

1-Aryloxyacyl-4,5,6,7-tetrahydroindazole obtained by the method $B$ was heated at $125^{\circ} \mathrm{C}$ for $3 \mathrm{hrs}$. After cooling, the solidified material was recrystallized from ethanol to give colorless crystals in quantitative yield. Melting point, and NMR and IR spectra of the product confirmed the identity with 2-aryloxyacyl-4,5,6,7-tetrahydroindazole obtained by the method A.

Acknowledgements. The authors wish to express their deep gratitude to Dr. S. Tatsuoka, Director of the Division, for permission to publish this report. Thanks are due to Dr. $T$. Harukawa of these laboratories for his encouragement. They are indebted to $\mathrm{Mr}$. M. Kan for elemental analysis, and to Miss F. Kasahara for the NMR spectra measurement.

10) H. M. Hill, G.W. Senter and M.E. Hill, J. Am. Chem. Soc., 72, 2286 (1950). 